\title{
What Do You Do With a Doctor that Does Not Make It into Specialist Training?
}

\author{
Quais São as Opções Profissionais para Médicos Que \\ Não Ingressam no Internato Médico?
}

Glen BANDIERA $\triangle^{1,2}$, Vivian TAM ${ }^{3}$

Acta Med Port 2018 Nov;31(11):612-613 - https://doi.org/10.20344/amp.11299

Keywords: Education, Medical, Graduate; Internship and Residency; Physicians/supply \& distribution

Palavras-chave: Educação de Pós-Graduação em Medicina; Internato e Residência; Médicos/provisão \& distribuição

Training future doctors is an expensive proposition, the cost of which is born to varying degrees by individual trainees and society at large. Selection criteria have been refined such that in many jurisdictions, particularly where a major portion of the cost is publically covered, most of those admitted to medical school eventually graduate. But what happens when medical school graduates are then prevented from entering practice due to lack of available residency positions? This has become a key question in North America, where residency training is required for licensure, and where the number of medical students who cannot secure such a residency position has risen rapidly in the past few years. ${ }^{1}$ This growing concern also heralds important opportunities for reflection about the nature of medical training: Should doctors have guaranteed employment or access to a career given their specific and time-intensive training? If so, how do we best match undergraduates' interests with postgraduate training capacity, while considering societal need? If not, what opportunities exist for the growing medical workforce with only a basic medical degree to their name?

In North America, the transition from undergraduate to postgraduate medical training is highly regulated. Graduating medical students prepare program-specific CVs, clinician reference letters, attend in-person interviews and then generate a rank-ordered list of their preferred postgraduate programs. Postgraduate programs generate their own rankordered lists of preferred graduates, and a computerized algorithm generates a binding 'match' between the graduate and their future training program. ${ }^{2}$ Graduates who go unmatched have few options; they are neither students, (and thus cannot secure insurance to undertake further clinical electives), nor licensed physicians (and thus cannot engage in remunerative clinical work). In other jurisdictions, including the UK and Australia, unmatched graduates can secure hospital posts that allow for restricted or supervised practice, and an opportunity to increase their appeal to formal residency training positions in subsequent years. In European Union member states, freedom of movement rules include automatic recognition of professional qualifications. This enables medical graduates who were not able to secure a residency position in their native country to pursue specialist training in another country.

In Canada, the ratio of available residency spots to applicants has decreased from 1.11:1 ten years ago to 1.02:1 in 2018, and the percentage of unmatched Canadian medical students has increased from $0.5 \%$ to $2.4 \% .^{1}$ This year, 69 Canadian medical graduates were not matched to any program despite completing two rounds of the match process. While the number itself is not large, the financial, emotional and practical costs on the individual are immense. With the cost of training a doctor estimated at C\$ 1 million ( $€ 660000)$, this year's unmatched cohort alone represents a $\mathrm{C} \$ 69$ million loss of investment ( $€ 46$ million). Additionally, there will be 69 fewer physicians serving the Canadian population.

There is a less tangible cost as well. Clinical training relies on experiential learning involving patient care. The risk and burden on patients of exposure to students at various levels of (in)experience is seen as a societal quid pro quo for sustaining a cohort of doctors in the future. Is it appropriate to ask patients to accept this burden if a higher proportion than is necessary of these trainees cannot eventually practice? Even programs designed for high attrition early on may need to consider this: more and more evidence supports integrated curricula that expose students to the more expensive and risky clinical learning milieu early on; as a result, this approach to attrition may become antiquated. ${ }^{3}$

One of the challenges is aligning graduating medical students' interests in medical specialty and practice location with societal need. Per the first recommendation from the Future of Medical Education in Canada (2009), the medical education system has a prime objective of delivering the right number, mix and distribution of physicians to meet societal needs. ${ }^{4}$ Simplistically, the 'number' is determined by enrollment in medical schools, the 'mix' by the allocation of training positions across specialties, and the 'distribution' by where physicians choose to practice. So what is

1. Emergency Physician. St. Michael's Hospital. Toronto. Canada.

2. Professor and Associate Dean, PGME. University of Toronto. Toronto. Canada

3. Family Medicine. University of Toronto. Toronto. Canada.

$\bowtie$ Autor correspondente: Glen Bandiera. bandieraG@smh.ca

Recebido: 18 de setembro de 2018 - Aceite: 18 de setembro de 2018 | Copyright @ Ordem dos Médicos 2018 
the cost when the mix of positions awaiting graduates does not align with their interests? In the past, the $1.11: 1$ ratio enabled some flexibility. When the ratio falls below 1:1 (as it did when language of training and practice were considered in 2016 in Canada), the risk of not securing a position increases. While it may seem easy to mandate those seeking positions to accept placement in remaining specialties, our experience has been that unhappy residents make for a higher risk of remediation, significant wellness issues, and poorer motivation to succeed in training. Many applicants would rather wait a year and try again than accept a placement in an undesired specialty. Since prior year graduates may ultimately compete for positions in subsequent years, this further decreases the position-to-eligible candidate ratios. The same is true in jurisdictions where medical school graduates can embark on general training or generalist independent practice; if and when they decide to pursue specialty training the applicant pool becomes inflated.

With annual tuition as high as C\$26 500 (€18 000), the individual burden is significant.

Furthermore, students applied for, on average, 20 programs in 2018 and the cost of travelling for electives and interviews ranges from $\$ 5000$ - \$30 000 (Survey data, personal communication). Average debt for Canadian medical graduates is therefore estimated to approximate C\$165 000 (€105 600). ${ }^{5}$ The financial burden creates both anxiety and, paradoxically, incites behaviours that exacerbate the problem. High debt loads force students to vie for highly remunerative specialties in which positions are scare, foregoing other specialties that pay less, but may provide more job opportunities reflective of societal need. In an editorial, Andre Picard makes the argument for a 'zero tuition' model of Canadian medical school with the aim of reducing medical student debt and attracting students to lower-paying generalist specialties, as well as curating a

\section{REFERENCES}

1. Canadian Resident Matching Service (CaRMS). R1 Data and reports. [accessed 2018 Sep 16]. Available from: https://www.carms.ca/datareports/r1-data-reports/.

2. Canadian Resident Matching Service (CaRMS). R-1 Main residency match. [accessed 2018 Sep 16]. Available from: https://www.carms.ca/ match/r-1-main-residency-match/.

3. Bandiera G, Kuper A, Mylopoulos M, Whitehead C, Ruetalo M, Kulasegaram $\mathrm{K}$, et al. Back from basics: integration of science and practice in medical education. Med Educ. 2018;52:78-85.

4. Association of Faculties of Medicine of Canada. The future of medical education in Canada. UG: the collective vision report. Ottawa: AFMC; 2009.

5. Association of Faculties of Medicine of Canada. Report: Future MD health workforce more representative of the socio-economic and cultural diversity of the society they will work in. ${ }^{6}$ This is the other issue presented by high tuition: the predilection for medical school cohorts to be over-represented by high socio-economic groups, since those with the means to afford medical education are more likely to apply. ${ }^{7}$

The perceived risk of being unable to practice and pay back substantial loans, and the prospect of not securing a residency position means that students become focused on reducing the likelihood of going unmatched. They undertake clinical electives nationwide, all the while 'auditioning' for residencies, rather than using the electives to round out educational gaps or explore new and interesting areas. The focus becomes getting a position, and not getting an education.

What options other than specialty training are there? Certainly, in the UK and other jurisdictions, individuals can practice for prolonged periods of time without specialist credentials. This is an important part of the workforce. However, the landscape of medical practice is changing. More and more, doctors are expected to master expanding spheres of knowledge and be competent in domains beyond medical expertise. The evolution of family medicine and emergency medicine as specialties in many countries emphasizes this transition, questioning the longevity of the purely generalist medical practitioner.

Medicine is unique for all of these reasons. The financial and emotional toll on individuals and the aggregate cost to society is simply too much to accept a high attrition rate and/or high rate of those who cannot pursue required further training.

\section{CONFLICTS OF INTEREST}

The author has no competing interests to declare.

Canada costs and funding: what will it cost to become a doctor? [accessed 2018 Sep 17]. Available from: https://afmc.ca/sites/default/ files/qa/Q3c.pdf.

6. Picard A. Why Canadian medical students should be offered free tuition Globe and mail. [accessed 2018 Sep 10]. Available from: https://www. theglobeandmail.com/opinion/article-why-canadian-medical-studentsshould-be-offered-free-tuition/.

7. Khan R, Leung R, Lew B, Sit D, Day L, Apramian T. Socioeconomic status as a determinant of medical school admissions. Ontario Medical Students Association. [accessed 2018 Sep 16]. Available from: https://omsa.ca/sites/default/files/position_paper/41/position_ paper_socioeconomic_status_as_a_determinant_of_medical_school admissions_2016_mar.pdf. 